\title{
O chapéu: Uma ferramenta para a identidade e a responsabilidade social no câncer de mama
}

\section{Poltronieri Lenzi, Gabriela}

Resumo:

Por meio do chapéu, um acessório da indumentária pouco utilizado atualmente, procurou-se aplicar sua técnica e seu uso em um grupo de mulheres portadoras de câncer de mama, onde seu papel foi relevante e auxiliar para a autoestima, bem-estar e identidade das mesmas. Além dos benefícios relacionados ao uso, também sua confecção foi um modo de exercitar a socialização e a sustentabilidade social, desenvolvidas ao longo de cinco meses em uma Oficina que aconteceu em uma Instituição Não Governamental, localizada em uma cidade do Sul do Brasil, que visa apoiar estas mulheres durante e após a doença.

\section{Cuadernos del Centro de Estudios de Diseño y Comunicación N76}

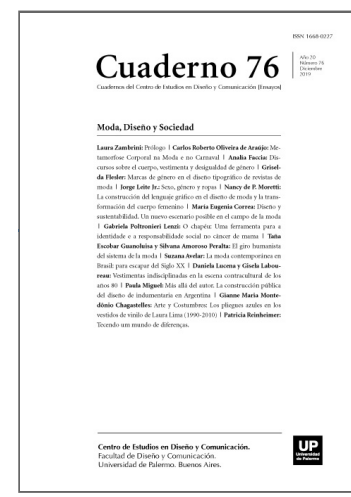

ISSN: 1668-0227

Moda, Diseño y

Sociedad

Año XX, Diciembre 2019, Buenos Aires, Argentina | 242 páginas

descargar PDF

ver índice de la publicación

Ver todos los libros de la publicación

compartir en Facebook

c) (i)(2) Esta obra está bajo una Licencia Creative Commons Atribución-NoComercialCompartirlgual 4.0 Internacional

Palavras chave:

Responsabilidade social - Sustentabilidade social - Autoestima - Chapéu - Câncer de mama - Identidade social Socialização.

(*) Bacharel em Moda e Estilismo Industrial - Universidade Regional de Blumenau - FURB, Brasil (2007). Mestra em Arte nella Moda - Accademia Italiana di Arte Moda e Design - Florença, Itália (2008). Mestra em Antropologia de Iberoamérica - Universidad de Salamanca - USAL, Espanha (2014). Doutoranda em Ciências Sociais, Linha de Antropologia - Universidad de Salamanca - USAL, Espanha. Atualmente realiza estágio docente na Universidade Regional de Blumenau - FURB, Brasil. Integrante dos Grupos de Pesquisa: GIIAC - Grupo de Investigacíon Internacional de Antropología del Cuerpo; CISMO - Cultura, Inovação, Sustentabilidade e Moda FURB; GEPES - Grupo de Estudos e Pesquisas sobre Educação Superior - FURB. 
No ano de 2014, ao se concluir a dissertação de mestrado que visou resgatar a antiga técnica da chapelaria, por meio de pessoas que desempenhavam tal ofício no passado século, notou-se que não somente a retomada de tal labor era expressiva, como também a sua aplicação a segmentos específicos, onde seu uso gerasse uma nova oportunidade tanto para esse elemento de moda que está em gradativo desuso desde as últimas décadas, quanto para sua aplicabilidade em grupos que necessitassem desse acessório por questões identitárias, sociais e/ou culturais (Lenzi, 2014).

Por meio dessa observação, decidiu-se aplicar a técnica aprendida em um grupo de mulheres que frequenta a Rede Feminina de Combate ao Câncer, da cidade de Blumenau, Santa Catarina, Brasil, supondo que elas poderiam confeccionar chapéus que seriam usados por elas mesmas, caso estivessem sem seus cabelos devido ao tratamento quimioterá- pico, ou então, se já estivessem curadas, com seus cabelos já crescidos, mas que desejassem frequentar tal Oficina, poderiam assim produzir chapéus que, posteriormente, seriam doados a colegas em tratamento naquele momento.

Nessa direção, encontrou-se em Ruiz (apud Salcedo, 2014, p. 43) a seguinte argumentação em defesa da sustentabilidade social dentro da moda: "qualquer atividade manual feita conscientemente é terapêutica: desenhar, fotografar, costurar (...)".

Tendo em vista tal afirmação, levantou-se a seguinte questão: como o desenvolvimento do chapéu pode ser uma ferramenta em busca da responsabilidade social, proporcionado a busca da identidade em mulheres enfermas de câncer? Assim sendo, objetivou-se compreender como esse elemento de moda, ou seja, o chapéu pode ser um alicerce à sustentabilidade social exercida por meio das pacientes que teriam a oportunidade de beneficiar colegas que vivem hoje o mesmo que elas viveram no passado.

Para tanto, esse artigo se compõe, primeiramente, da metodologia, que explana o campo estudado, bem como aborda o caráter da pesquisa e o método escolhido para melhor responder à questão da pesquisa.

Posteriormente, faz-se uma contextualização do campo, na qual, de maneira descritiva, apresenta-se a Oficina do Chapéu, os temas abordados pelos sujeitos da pesquisa e a progressão desse trabalho em grupo. Na seção

"Responsabilidade Social: O Chapéu como Protagonista" conceitua-se a sustentabilidade social presente nesse projeto e descrevem-se as iniciativas individuais e do grupo para promover um benefí- cio social. Alguns dos principais benefícios ocasionados encontram-se expressos na seção "A Identidade Reforçada por meio do Chapéu e das Relações Sociais", onde, por meio do acessório, os sujeitos expressam seus ganhos de autoestima e bem-estar, gerados por fatores estéticos e de socialização.

\section{Metodologia}

A pesquisa ora apresentada é um fragmento do estudo que se realizou para a tese de doutoramento e, nesse específico artigo, se apresenta um recorte com foco na responsabilidade social, bem como em fatores identitários e de socialização gerados. Essa experiência se deu na Rede Feminina de Combate ao Câncer da cidade de Blumenau, Santa Catarina, Brasil, onde se conviveu intensivamente com trinta mulheres como observador plenamente participante incorporado ao estudo, sendo que se fez a extração dos relatos do diá- rio de campo, bem como de gravações de áudio feitas durante os encontros com o grupo. O diário de campo, para Guber (2001), pode servir como um guia para as futuras entrevistas, apontando os pontos a serem aprofundados. Também cumpre a função de manter os comentários do observador registrados durante o 
trabalho de campo, momento em que esse se coloca como observador participante, e, finalmente, de registrar a conversa fora do ambiente das entrevistas. Assim, além das conversas entre pesquisador/sujeito, o diário de campo permite o registro das observações e o relato das conversas entre os sujeitos da pesquisa e das reações geradas pela socialização.

Esse estudo sustenta-se na antropologia aplicada que visa não somente interpretar e compreender o mito cultural de um determinado grupo, mas também atuar dentro dele, onde a antropologia perpassa a ela mesma (Salazar, 2008). Acredita-se, porém, que a antropologia aplicada não seja um campo próprio, mas que emirja da antropologia tradicional ou até mesmo, conforme afirma Peacock (1989, pp. 170-171), que a antropologia em si possua um cunho necessariamente aplicado, pois:

En su investigación erudita, la antropología ya es aplicada porque se ve envuelta en los grupos humanos a través de la observación participativa. En el trabajo de campo, el antropólogo se enfrenta a cuestiones éticas, debe resolver tareas prácticas y, le guste o no le guste, todo eso afecta a él y al grupo... El trabajo de campo puede tener nobles propósitos académicos, pero se lleva a cabo en un contexto de necesidades humanas y de relaciones humanas, de las que no es posible escapar1.

Tendo como base tais afirmações a respeito da antropologia aplicada, desenvolveu-se uma oficina, a qual se denominou de Oficina do Chapéu, onde nove pacientes e quatro voluntárias na instituição confeccionaram vinte e dois chapéus e dezesseis mulheres que viviam os efeitos colaterais da quimioterapia foram contempladas com o acessório desenvolvido. A Oficina teve a duração de cinco meses, com encontro uma vez na semana. Três das mulheres que confeccionaram seus chapéus fizeram uso deles, pois encontravam-se sem seus cabelos, e o restante dos chapéus foi doado às outras pacientes que, devido à debilidade física ocasionada pela quimioterapia, não puderam participar ativamente da Oficina.

O propósito dessa Oficina consistiu na aplicação de um acessório da indumentária em desuso no momento atual para favorecer a qualidade de vida psicológica e emocional das pacientes acometidas pelo câncer, enaltecendo a autoestima e reforçando a identidade cultural feminina dessas mulheres, bem como para promover a socialização, gerando assim a troca de experiências entre as pacientes, tanto as já curadas quanto as ainda acometidas pelo câncer, e, finalmente, proporcionando uma terapia. Havia, portanto, dois grupos distintos de mulheres no projeto: as que estavam passando pelo tratamento quimioterápico e que usariam o chapéu para cobrirem suas cabeças carecas e, assim, terem uma possibilidade de aumento de autoestima, e as que já haviam passado pela enfermidade, que se encontravam fora da quimioterapia, porém ainda necessitando de tratamento pós-câncer, como fisioterapia, acompanhamento psicológico e social. Esse grupo seria beneficiado com o trabalho manual dos acessórios.

De caráter qualitativo, a pesquisa utilizou-se do método etnográfico para coletar e interpretar os dados. Para Kottak (2013), a etnografia nasce como uma estratégia de pesquisa que busca compreender o todo de uma cultura. Para tal, os etnógrafos desenvolvem um método amplo e livre de coleta de dados. Assim, o etnógrafo, "Em uma dada sociedade ou comunidade, [...] se move de um contexto a outro, de uma pessoa a outra e de um lugar a outro para descobrir a totalidade e interconectividade da vida social" (Kottak, 2013, p. 71).

Por adotar o método etnográfico, escolheu-se assumir uma postura de observador participante, técnica característica dessa estratégia que supõe que a compreensão de um contexto social específico só possa ser 
concretizada se o observador imergir no grupo que está estudando e dele se transformar um membro (Fraser \& Gondim, 2004).

Comprovando a ética e o respeito com que se adentrou o campo, submeteu-se esse estudo ao Comitê de Ética Humano do país onde se desenvolveu a pesquisa, sendo aprovado em dezembro de 2015. Assim, cada sujeito assinou o Termo de Consentimento Livre e Esclarecido (TCLE), o que the garante proteção e integridade no decorrer do estudo. As mulheres participantes concordaram em serem gravadas, tanto com áudio como com vídeo, e permitiram a captação fotográfica, autorizando assim o uso de imagem.

Além da pesquisa empírica, principal fonte de informação dessa pesquisa, realizou-se um levantamento bibliográfico específico que permitiu a organização do material a ser utilizado. Esse levantamento foi relevante durante todo o processo de estudo, acompanhando o seu desenvolvimento e a sua sequência, demarcando pontos-chave e gerando conhecimento antecipado a respeito do tema tratado, além de solidificar e embasar a experiência vivida em campo.

Empatia e doação: uma contextualização do campo estudado

Embora o convite e as explicações já tivessem acontecido na metade do ano de 2015, em início de março do corrente ano, aproximadamente quinze rostos olhavam curiosos para compreender no que realmente consistiria a Oficina do Chapéu. Mesmo estando já inscritas, suas curiosidades mesclavam o desejo de colocar as mãos rapidamente nos feltros coloridos de lapin2 e um certo medo de talvez não conseguir confeccionar um chapéu, tudo banhado com o mais puro desvelo, pois um chapéu seria feito. “-Mas eu não preciso entender nada de chapéu, né? É só vir e você ensina?" perguntou Marly. Aos poucos, no decorrer das conversas, elas serenaram ao saberem que bastaria ter vontade e comparecer todas as quartas-feiras de manhã na instituição que, ao final, teriam os chapéus em mãos. A tranquilidade maior se deu quando descobriram o motivo da confecção desses chapéus: doação. Doação a mulheres que, assim como elas, sentiam naquele momento o que elas sentiram no passado: o medo ao descobrir o câncer, as dores, os efeitos colaterais da quimioterapia, a cirurgia, a perda de referenciais sociais e identitários femininos. Quem melhor do que essas mulheres param se tornarem as mãos das colegas que, pela debilidade física, não poderiam frequentar a Oficina para confeccionar os próprios chapéus? Sem dúvida alguma, essas são as melhores mãos para tal ofício. Cada ponto dado naquele feltro era carregado com muita empatia, desejo de cura e a maior prova de que é possível sobreviver ao câncer, pois elas estavam lá, vivas, costurando os chapéus. Como mencionado anteriormente, três das mulheres inscritas na Oficina puderam fazer os próprios chapéus, ou seja, confeccionaram o acessório que usariam. Elas encontravam-se sem seus cabelos devido ao tratamento quimioterápico que ocorria no mesmo período em que a Oficina estava em andamento na instituição.

Os olhos que tinham expressão de curiosidade, ao poucos, marejaram, e a razão para fazer os chapéus tomou outra proporção: era muito mais que fazer um chapéu. Era levar esperança, apoio, bem-estar, autoestima, beleza para aquelas mulheres.

Nas semanas que se seguiram, fizeram-se testes de pontos e bordados que possibilitaram a elas perceber a textura do feltro, escolher a agulha ideal para ele e perder, pouco a pouco, o medo de experimentar. Inicialmente, somente algumas se conheciam, o que fez com que tendessem a ficar no círculo de amizade já 
existente ou, então, a se manter em silêncio, tímidas, embora, nas pausas para o café, algumas buscassem interagir.

Já em metade de abril do ano de 2016, se fez a entrega das bases do chapéu ao grupo. Moldaram-se os chapéus anteriormente, pois isso exige lavanderia, ferro a vapor e espaço para a secagem que não poderiam ser encontrados na instituição. Assim sendo, elas receberam os chapéus já moldados, mas ainda brutos, carentes de corte dos excessos e de adornagem. Nos encontros, entusiasmadas, escolheram as cores e os modelos, embora soubessem que não seriam elas que os usariam. Deixaram claro que os fariam como se fossem para si mesmas. Experimentaram os chapéus ainda inacabados e se exibiram para fotos com eles. Deuse prioridade de escolha àquelas que, por estarem sem seus cabelos, usariam os chapéus que confeccionariam. (Ver Figura 1)

Após a entrada dos chapéus na Oficina, entraram também mais conversas e diálogos entre as participantes. Os lugares onde escolhiam sentar já não dependiam da aproximação de uma conhecida de antes da Oficina.

Em um determinado dia, em meados de maio, Márcia, de maneira espontânea e natural, falou: “-Eu acho que todas aqui deveriam contar suas histórias, como descobriram o câncer, como reagiram... assim, para saber. Eu queria contar minha história e também queria saber as histórias das outras!"

E assim foi feito. Umas falaram mais facilmente sobre suas histórias, outras levaram mais tempo para se abrirem, embora o clima de confidência e amizade gerado proporcionasse, cada vez mais, espaço para a conversa e a troca de experiências acontecerem. A partir daí, conversaram sobre diversos temas: família, reações da quimioterapia, como lidaram com a doença, médicos, tratamentos alternativos, questões estéticas.

As mulheres que confeccionaram os chapéus para si mesmas foram as primeiras a terminar, pois estavam ansiosas para vestirem suas cabeças com suas obras. Além de mais uma opção de acessório, queriam mostrar os chapéus que elas mesmas produziram.

Débora, uma das usuárias do chapéu que conseguiu produzir seu próprio acessório, entrou para o grupo quando ele já estava em andamento, ou seja, já havia começado. Isso, porém, não fez com que seu rendimento ficasse para trás das outras companheiras. Além de conseguir confeccionar o chapéu rapidamente, pois queria usá-lo logo, conseguiu um entrosamento instantâneo com o grupo. Assim como ela, Tânia e Vera, que também confeccionaram e passaram a utilizar os chapéus que construíram, tinham um desejo: mais que poder usar seus chapéus o quanto antes e exibi-los, queriam fazer chapéus para outras mulheres. Sentiam urgência e necessidade de tal feito: queriam que essas mulheres que nem conheciam pessoalmente tivessem a mesma sensação que elas. Igualmente queriam o sentimento de doação e, embora não soubessem quem eram as mulheres que os ganhariam, sabiam perfeitamente o que sentiam.

Conforme os dias passaram, o enlace entre elas se fortaleceu. Já ao final, faltando pouco menos de um mês para a conclusão da Oficina, perguntaram, em tom triste, o que fariam nas futuras manhãs de quartas-feiras.

Em metade de julho de 2016, já com os chapéus concluídos e a lista de pacientes que os receberiam formada, resolveu-se fazer uma espécie de comemoração de fechamento de um ciclo, uma despedida dos chapéus, com 
os quais elas conviveram por quase cinco meses e nos quais depositaram muito amor. Assim, fez-se uma sessão de fotos na qual elas posaram com os chapéus em suas cabeças pela última vez (Ver Figura 2).

Nesse dia, o grupo ainda se encontrava em seu formato inicial, pois seu desdobramento foi necessário e recebido por todas com resiliência e brandura. Em síntese, esse dia da sessão de fotos foi como um rito de passagem. Passam-se os chapéus, passa-se todo o carinho com o qual foram feitos, passam-se os desejos de cura.

Desse modo, quinze dias depois, ocorreu, então, o dia da entrega do acessório, em que as mulheres que se encontravam carecas receberam o objeto (Ver Figura 3). Elas não conseguiam esconder a excitação do encontro, de poder escolher o chapéu que tanto esperaram. Nem todas as recebedoras do acessório puderam estar presentes no dia da entrega, justamente por questões de mal-estar físicas ocasionadas pela quimioterapia. Essas receberam os chapéus nas semanas que sucederam o evento, conforme lhes era possível. Porém, mesmo assim, tiveram a oportunidade de escolher seu chapéu, devido ao número excedente deles, pensados propositalmente para que todas tivessem direito de escolha, pois acredita- -se que cada uma tenha o poder de tutelar sua própria identidade. Também o design do acessório foi projetado para suprir exatamente o conforto e a estética exigidos por uma cabeça sem cabelos.

Responsabilidade social: o chapéu como protagonista

Embora a responsabilidade social sustentável seja vista, geralmente, como um compromisso corporativo, o indivíduo também pode e deve desempenhar sua função dentro da sociedade onde vive. Para Marques (2014), por meio da sustentabilidade social, é possível evidenciar o papel dos indivíduos e da sociedade.

Com essa visão, a Oficina do Chapéu, implantada na Rede Feminina de Combate ao Câncer, fundamentou-se na inclusão de valores sociais, além de que, por meio dela, as mulheres participantes dessa pesquisa puderam não somente desenvolver habilidades ou explorar habilidades preexistentes, mas também desenvolver capacidades de relacionamento e bem-estar social. Isso porque os chapéus produzidos por elas tiveram o intuito de vestir as cabeças das colegas que estavam em tratamento quimioterápico, assim como elas já estiveram um dia.

Ainda que a instituição onde foi realizada a Oficina do Chapéu seja de filantropia, ou seja, sua base nasça da sustentabilidade e responsabilidade social, foi na Oficina que essas mulheres puderam desempenhar seu papel social individual. "-Eu sempre pensava que quando estivesse curada do câncer, também queria fazer o bem para outras mulheres, como fizeram aqui na Rede, para mim", disse Vera que, além de paciente, passou a ser voluntária e integrante do grupo Oficina do Chapéu. Além dela, Andiara, que recebeu os chapéus, se sensibilizou e, se inspirando nas colegas e ainda passando pela quimioterapia, já planeja sua futura participação em uma Oficina como essa.

Para Gwilt e Rissanen (2011), a sustentabilidade baseia-se em um tripé que consiste em fatores de equilíbrio entre o social, o econômico e o ecológico. Já Sachs (1993) inclui, além desses três elementos, a sustentabilidade espacial, que consiste na melhor distribui- ção territorial, e a cultural, que visa respeitar a especificidade de cada cultura. Embora o foco principal da Oficina do Chapéu tenha sido no fator social da sustentabilidade, também uma parte dos materiais utilizados para adornar, como rendas e bordados, foi de 
reaproveitamentos doados por privados e por indústrias da região. Isso significa que princípios ambientais e econômicos foram adotados, bem como de sustentabilidade cultural, buscando uma solução particular para o grupo de mulheres que, acometidas pelo câncer, sofrem com questões identitárias, efeito colateral do tratamento, assim como menciona Okada e Berlin (2014, p. 13):

Para transformar modos de vida e estimular novos comportamentos sociais, seria importante entender a dinâmica da Moda, a sua função cultural para a identidade individual e social e de sua amplitude nas sociedades contemporâ- neas. Também é preciso conhecer os padrões culturais estabelecidos e de possibilidades de mudanças em relação ao bem estar e qualidade de vida.

Além dos benefícios gerados às mulheres que receberam o chapéu, e do papel social desempenhado, as chapeleiras da Oficina puderam desenvolver suas competências e habilidades. Lourenço e Carvalho (2013, p. 16) expõem que os conceitos de sustentabilidade social têm evoluído consideravelmente nos últimos anos, o que proporciona critérios mais modernos e atuais:

(...) Dyllick e Hockerts (2002) apontam que, no nível das corporações, a sustentabilidade social pressupõe que as organizações adicionem valor para as suas comunidades, a partir do desenvolvimento do capital humano de indiví- duos e do capital social das comunidades. Ahmed e McQuaid (2005) balizaram que o conceito de sustentabilidade social enfatiza a administração de recursos sociais, incluindo pessoas e suas competências e habilidades, instituições, relacionamentos e valores sociais.

Lourenço e Carvalho (2013) ressaltam que frequentar o grupo e aprender a fazer os chapéus fez com que se sentissem úteis e encorajadas de suas habilidades. Algumas das participantes se aposentaram após a doença, outras ainda se encontram afastadas do trabalho. Além disso, devido à mastectomia radical, sentem dores nos braços e inchaço nas mãos, dependendo do movimento que devem realizar e do tempo que ficam em cada atividade. Marques (2014) acredita que a sustentabilidade social não somente beneficia as atuais gerações, mas também as gerações futuras. Com base nessa afirmativa e com o desenvolver da Oficina do Chapéu, supõe-se que essa foi a primeira de outras que virão. As mulheres que confeccionaram o acessório mencionavam o quanto gostariam de ter recebido esse adorno enquanto faziam o tratamento, além de manifestarem o interesse em participar novamente desse aprendizado. Devido aos resultados, a Instituição Não Governamental também expressou seu desejo de manter a Oficina e, por causa dela, amadurecem e estudam a possibilidade de outros cursos de habilidades manuais que beneficiem mulheres em tratamento contra o câncer.

Combinar responsabilidade social com um acessório de moda que, nos dias atuais, é pouco utilizado, porém, que serve ao grupo de mulheres que se encontra sem os cabelos, devido à quimioterapia, é revitalizar uma antiga técnica de moda, ou seja, é tornar sustentável tal conhecimento, reciclando-o e aplicando-o onde o mesmo tem utilidade. Da mesma forma, é, por meio dele, revitalizar, também, o bem-estar social e identitário dessas mulheres: as acometidas pelo câncer atualmente recebem uma possível oportunidade de aumento de sua autoestima; as já curadas recebem a possibilidade de exercitar a cidadania e desenvolver uma habilidade manual. Ambas, porém, cultivam novas amizades por meio dessa socialização gerada por esse acessório.

A identidade reforçada por meio do chapéu e das relações sociais 
Para Laver (1989), desde os últimos povos paleolíticos da Era Glacial, o ser humano sentiu a necessidade de aquecer-se, criando roupas e acessórios beneficiados a partir da pele animal, que era mastigada para ser curtida e, posteriormente, costurada e moldada de acordo com a parte do corpo que vestiria. Estima-se que, dessa necessidade de proteção do frio, a cabeça também tenha sido privilegiada.

A proteção da cabeça, seja por fatores climáticos ou atritos externos, que pediam o uso de capacetes protetivos, por exemplo, foi um dos assuntos discutidos pelas mulheres acometidas pelo câncer. Elas se referiam ao uso do chapéu, ou de qualquer outro adereço, como a peruca ou o lenço, como uma necessidade para proteger a cabeça careca. "-Não dá pra ficar com a cabeça assim exposta, tem que ter alguma coisa para proteger", afirmou Débora, com os cabelos tímidos recém-saídos do couro cabeludo.

Ao ser interrogada quanto a que tipo de proteção seria essa, ela mencionou a proteção ao sol, que poderia queimar a pele sensível da cabeça, ao frio que sentia durante o inverno que viveu sem cabelo e, por fim, a proteção dos "olhares de pena" da sociedade. Para ela, essa é a principal proteção.

Desse modo, percebe-se, nitidamente, que o chapéu não se sustenta somente em sua proteção física inicial. A proteção do chapéu exigida por elas nasce, também, do desejo de proteção social. Sua doença, mas, principalmente, os efeitos colaterais do tratamento, as transforma em estigmas sociais, ou seja, possuem traços distintos da normalidade aceita pela sociedade (Goffman, 1988).

Débora mencionou, ainda, que, diferente do lenço ou da peruca, o chapéu lhe proporcionou justamente esse distanciamento de parecer-se estigmatizada socialmente. Segundo ela, o uso tanto do lenço quanto da peruca já a apontavam como uma doente de câncer. Com o chapéu, as pessoas viam, antes da doença, uma mulher a ser admirada por sua beleza, conforme comentou: "-As pessoas dizem: 'Nossa, você fica muito estilosa com esse chapéu".

Como Débora, as outras mulheres da oficina também expressaram esse mesmo sentimento. Não queriam a compaixão do outro, mas queriam ser vistas por meio de sua identidade, independentemente da enfermidade. Para Vanni (2004, p. 45), quando um indivíduo se veste com um chapéu, esse explicita sua identidade, ou seja, expõe o que de fato deseja externar socialmente e oculta o que não quer que seja percebido pelo outro:

(...) un individuo che indossa un cappello tutela la propria identità. Oppure ne cerca una nuova. Alterando il corpo con un cappello si rende una persona differente dalle altre attraverso un linguaggio visivo; infatti il copricapo rappresenta una comunicazione nell'interazione sociale3 .

O ato de adornar-se para apresentar sua identidade social e interagir socialmente expressa uma caraterística natural humana. Estudos antropológicos afirmam essa tendência do ser humano: a prática de enfeitar-se. Para Benthall (1976); e Polhemus e Procter (1978), as pessoas, analisadas de uma maneira universal, possuem, desde sempre, uma predisposição a adornar-se. Entwistle (2002) destaca que esse argumento é amplamente aceito até hoje por pesquisadores da área da moda, levando em conta, justamente, essa prova antropoló- gica de que diversas culturas vestem seus corpos e que nenhuma o deixa sem adornar de algum modo.

Adornar-se com o chapéu confeccionado na Oficina do Chapéu gerou a possibilidade de uma aproximação social, conforme expressou Marina: "-Quando eu coloquei o chapéu, eu fiquei mais feliz, porque eu me sentia 
bem... aí eu fui fazer a quimioterapia com o chapéu e todos lá do hospital me elogiavam, queriam provar (o chapéu), perguntavam onde consegui o chapéu... e isso me fez me abrir e conversar, aí eu fiz mais amizades".

A fala de Marina denota que, com sua identidade reafirmada e sua autoestima elevada, foi possível uma maior abertura social para se expor. Para Hoffmann; Müller e Rubin (2009), os efeitos colaterais gerados pelo tratamento do câncer perpassam o campo físico e invadem o emocional e o psicológico, alterando, inclusive, a vida social da mulher, além dos problemas relacionados com a autoimagem. Porém, embora seja um momento que mude socialmente para essas mulheres, esse envolvimento é visto como positivo para que consigam enfrentar a doença do modo mais natural possível: "Por isso, é importante para a mulher sentir que tem uma rede de apoio social, que não a permite desistir, e que torne mais fácil o enfrentamento da doença" (Bermasco, 2001 apud Vieira; Lopes \& Shimo, 2007, p. 314). Outro fator de socialização desencadeado por meio da Oficina do Chapéu foi a relação gerada entre elas mesmas. As que frequentavam a Oficina trocavam experiências sobre a vida após e durante o câncer no decorrer dos encontros semanais. Assim que elas conheceram as mulheres que receberam os chapéus, também desenvolveram novas relações. Maristela, uma das acometidas pelo câncer atualmente, comentou que, após ganhar o chapéu, ganhou também novas amigas que a contatam quase que diariamente, apoiando-a e estimulando-a durante esse processo delicado. Para ela, além do prazer proporcionado pela amizade, também a inspiração de mulheres já curadas da enfermidade que enfrenta agora a encoraja e gera esperança.

\section{Considerações finais}

A responsabilidade social pode ser vivenciada por todo e qualquer indivíduo que deseja exercê-la. Certamente, por meio de instituições e organizações que facilitem esse processo, unindo grupos e proporcionando espaços e situações, torna-se mais palpável e acessível. Talvez as mulheres participantes dessa pesquisa nunca tenham imaginado que pudessem auxiliar dessa maneira as colegas que estavam passando pela mesma situação que elas já passaram e conheciam tão bem, embora sempre tenham tido o desejo de serem facilitadoras nessa situação. Existiram benefícios para as pacientes que receberam os chapéus, mas também houve benefícios para as pacientes que os confeccionaram, as quais, mesmo curadas e fora da quimioterapia, necessitam de tratamento e acompanhamento pós-câncer, tanto físico, quanto psicológico, social e identitário. O chapéu e o cuidado ofertados à colega é um modo de cuidar de si mesma, de abraçar esse passado que despertou dores e conflitos, mas também de ter autoconhecimento e resiliência. A empatia gerada na Oficina do Chapéu não somente proporcionou o colocar-se no lugar do outro. Como essas mulheres já estiveram nesse lugar, agora confortam seus pares.

Talvez qualquer trabalho manual ou artesanal levasse a tal resultado. Contudo, o chapéu, por ser um elemento enigmático, embora pouco visto em uso atualmente, desperta a curiosidade tanto de quem o aprecia como de quem o usa. Até o último século, determinados modelos de chapéus designavam a classe social; hoje, somente o fato de usar chapéu tutela a identidade do indivíduo. Além disso, um chapéu não é comparado a outro, mas divide seu lugar com cabeças que andam sem chapéu.

Embora a queda dos cabelos seja somente uma de todas as consequências tanto do tratamento, bem como da doença, as mulheres dessa pesquisa sabem que perdê-los não significa somente não ter mais uma cobertura sobre a cabeça, que protege do frio ou do sol ou de fatores funcionais. Perdê-los também significa perder parte de si mesma pela qual se conhecia, se reconhecia e era reconhecida pelos outros. Sua identidade social e 
cultural é questionada e, embora seja possível reconstruir-se a partir daí, pode deparar-se com desafios constantes nessa nova redescoberta de seu eu. E é nessa circunstância que um acessório como o chapéu assume uma de suas mais nobres funções.

Notas

1. "Na investigação erudita, a antropologia já é aplicada porque se vê envolta nos grupos humanos através da observação participante. No trabalho de campo, o antropólogo se confronta com questões éticas, deve resolver tarefas práticas e, goste ou não, tudo isso afeta a ele e ao grupo... O trabalho de campo pode ter nobres propósitos acadêmicos, porém deve-se levar em conta o contexto de necessidades humanas e relações humanas, da qual não é possível escapar" (Tradução nossa).

2. Coelho (Tradução nossa).

3. “(...) um indivíduo que veste um chapéu tutela a própria identidade ou procura uma nova. Alterando o corpo com um chapéu, se transforma em uma pessoa diferente das outras, por meio de uma linguagem visual; de fato, o chapéu representa uma comunicação na interação social" (Tradução nossa).

\section{Referências}

Benthall, J. (1976). The Body Eletric: patterns of western industrial culture. Londres: Thames And Hudson.

Entwistle, J. (2002). El cuerpo y la moda - una vision sociológioca. Barcelona: Paidós Contextos.

Fraser, M. T. D. \& Gondim, S. M. G. (2004 Maio 08). Da fala do outro ao texto negociado: discussões sobre a entrevista na pesquisa qualitativa. Paidéia, 14 (28): 139-152. Disponível Em: .

Goffman, E. (1988). Estigma: notas sobre a manipulação da identidade deteriorada. Rio de Janeiro: LTC.

Guber, R. (2001). La Etnografía: método, campo y reflexividad. Buenos Aires: Editorial Siglo Veintiuno.

Gwilt, A. \& Rissanen T. (2011). Shaping Sustainable Fashion: changing the way we make and use clothes. 1a ed. London: Earthscan.

Hoffmann, F. S.; Müller, M. C. \& Rubin, R. (2009). A mulher com câncer de mama: apoio social e espirituralidade. Mudanças-Psicologia da Saúde, 14 (2): 143-150.

Kottak, C. P. (2013). Um espelho para a humanidade: uma introdução à antropologia cultural. Porto Alegre: AMGH Editora.

Laver, J. (1989). A roupa e a moda: uma história concisa. São Paulo: Companhia das Letras.

Lenzi, G. P. (2014). Memórias de pessoas e de chapéus em Blumenau, Brasil, e Florença, Itália. Dissertação de Mestrado em Antropologia de Iberoamerica, Universidad de Salamanca. 
Lourenço, M. L. \& Carvalho, D. (2013). Sustentabilidade social e desenvolvimento sustentável. Race, 12 (1). Disponível em: .

Marques, W. L. (2014). Sustentabilidade não tem cara, mas tem vida. Cianorte, PR. Disponível em: .

Okada, R. A. \& Berlim, L. (2014). Design de moda: possibilidades de inovação social e sustentabilidade. Iniciação-Revista de Iniciação Científica, Tecnológica e Artística, 4 (2): 1-22.

Peacock, J. L. (1989). El enfoque de la antropologia. Luz intensa, foco difuso. Barcelona: Herder.

Polhemus, T. \& Procter, L. (1978). Fashion \& anti-fashion: anthropology of clothing and adornment. London: Thames And Hudson.

Sachs, I. (1993). Estratégias de transição para o século XXI. São Paulo: Nobel.

Salazar, S. H. (2008). El valor de la aplicación etnocultural. In: Barrio, A; Barrio, E. Antropología Aplicada En Iberoamérica. [pp. 153-169, Coletânia]. Recife: Fundação Joaquim Nabuco.

Salcedo, E. (2014). Moda ética para um futuro sustentável. São Paulo: Editora G. Gili Ltda.

Vanni, M. (2004). Creatività, espitazione, consapevole illusione e il cappello de carta (III Capitulo). In: . Identità e diversità. Il cappello e la creatività: a cura de Maurizio Vanni. Siena: Carlo Cambi Editore. [pp. 43-50]. Siena: Carlo Cambi Editore.

Vieira, C. P.; Lopes, M. H. B. D. M. \& Shimo, A. K. K. (2007). Sentimentos e experiências na vida das mulheres com câncer de mama. Rev Escola de Enfermagem da USP, 311-316.

Resumen: Se buscó aplicar, en un grupo de mujeres que padecen cáncer de mama, la técnica y el uso del sombrero, considerándolo como un accesorio de la indumentaria que, además de poco utilizado actualmente, tuvo un papel relevante y de ayuda en el autoestima, en el bienestar y en la identidad de estas mujeres. Además de los beneficios relacionados con el uso del sombrero, también su confección fue un modo de fomentar la socialización y la sustentabilidad social, a través de reuniones desarrolladas a lo largo de cinco meses en una Institución No Gubernamental localizada en el sur de Brasil que busca apoyar estas mujeres durante y después de la enfermedad.

Palavras clave: Responsabilidad social - Sustentabilidad social - Autoestima - Sombrero - Cáncer de mama Identidad social - Socialización.

Abstract: Purpose was to apply to a group of women with breast cancer technique and usage of the hat, an accessory of clothing which, however seldom used in these days, has played a relevant and auxiliary role in wellbeing and identity of these women. Aside from benefits related to wearing it, its making was a means of exercising socialization and social sustainability developed throughout five months in a workshop that took place in a NonGovernmental Organization located in a city of Southern Brazil which aims to support these women during and after the disease. 
Key words: Social responsibility - Social sustainability - Self-Esteem - Hat - Breast cancer - Social identity Socialization.

[Las traducciones de los abstracts fueron supervisadas por el autor de cada artículo]

O chapéu: Uma ferramenta para a identidade e a responsabilidade social no câncer de mama fue publicado de la página 105 a página117 en Cuadernos del Centro de Estudios de Diseño y Comunicación №76 